\title{
Preoperative clinical predictors of long term survival in mitral stenosis: analysis of 200 cases followed for up to 27 years after closed mitral valvotomy
}

\author{
PC GAUTAM, N COULSHED, EJ EPSTEIN, MJ LLEWELlyN, E VARGAS, \\ RC TALLIS
}

\begin{abstract}
From the Regional Adult Cardiac Cardiothoracic Unit, Broadgreen Hospital, and the University Department of Geriatric Medicine, Liverpool
\end{abstract}

ABSTRACT Two hundred patients aged 17-40 years undergoing closed mitral valvotomy during 1955-60 were studied by actuarial survival analysis. The period of follow up was 22-27 years. The following preoperative features were found to be independent predictors of long term survival: sinus rhythm ( $<<0.05)$; pulmonary arterial pressure below systemic pressure $(\mathrm{p}<0.01)$; absence of congestive cardiac failure $(p<0.01)$ and pure mitral stenosis $(p<0.01)$. A better long term survival was found for mitral valvotomy with a Tubb's dilator than finger splitting or Brock's method. The presence of calcification at the time of valvotomy adversely affected survival $(p<0.01)$. Anticoagulation improved survival $(p<0.01)$. It is concluded that closed mitral valvotomy gives good results if performed before the onset of established atrial fibrillation and congestive cardiac failure and that all patients should have anticoagulation. These results have important implications for selection of patients in countries with limited facilities for open heart surgery.

The symptomatic and haemodynamic improvements brought about by commissurotomy in rheumatic mitral stenosis have been well documented. ${ }^{2}$ The emphasis in current publications is on open heart surgery in mitral stenosis and the relatively simple method of closed mitral valvotomy tends to be overlooked. ${ }^{2-4}$ This may be unfortunate because most rheumatic mitral valve disease occurs in developing countries where modern expensive facilities for cardiological investigation and open heart surgery are not usually available. ${ }^{5-7}$ There is, however, evidence of some recent revival of interest in closed mitral valvotomy and confirmation of its value in the long term relief of symptoms. ${ }^{89}$

A recent report of the outcome in over 600 patients attempted to identify clinical predictors of survival. ${ }^{10}$ Nevertheless, there is still considerable disagreement about the long term effects of mitral valvotomy. ${ }^{11-13}$

The present study aimed to identify specific features of mitral stenosis that would predict long term survival in patients undergoing closed valvotomy. We

Address for reprint requests: Dr PC Gautam, 61 South Barcombe Road, Childwall, Liverpool L16 7QE.

Accepted 9 September 1985 have analysed data on 200 consecutive patients who had been treated in this way 22-27 years previously.

\section{Methods}

SELECTION AND FOLLOW UP OF PATIENTS

We studied records of 218 consecutive patients, aged 17-40 years, who underwent closed mitral valvotomy in Liverpool from January 1955 to December 1960. The eight patients who had had a previous valvotomy elsewhere and a further 10 suffering from systemic illnesses (for example, diabetes mellitus) were excluded. The resulting sample consisted of 200 patients, 42 men and 158 women.

The patients had initially been referred to Liverpool from a wide area covering North Wales, Merseyside, and Lancashire. Data were collected by examining case records, operation notes, personal records of the cardiologists, and communications from referring physicians and family practitioners obtained in response to a simple postal questionnaire.

A second closed valvotomy was done on those patients who showed progressive deterioration in symptoms - for example, paroxysmal nocturnal dyspnoea, palpitations on exertion, and congestive cardiac failure (New York Heart Association (NYHA) 
Table 1 List of variables studied in each case

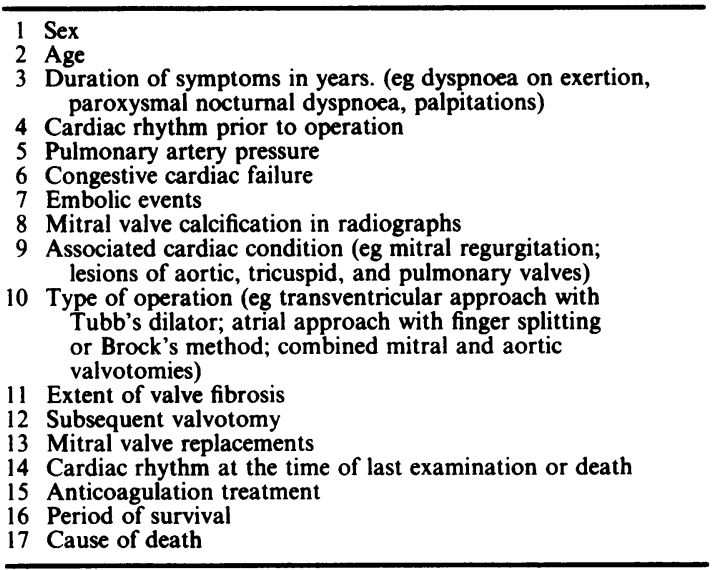

functional class III or IV) despite maximum medical treatment. All such patients were assessed by cardiac catheterisation, including coronary angiography. Those patients who were considered unsuitable for repeat valvotomy were given mitral valve prostheses.

The information recorded at the time of the last medical contact was used for analysis of those patients lost to follow up. All patients attending the cardiothoracic centre were seen by one of us from January to June 1983. In the case of patients known to have died, the cause of death and events leading to death were established by inspecting the hospital case records, records kept by family practitioners, and necropsy reports where available.

\section{THE VARIABLES STUDIED}

Seventeen items of information were obtained about each patient and used in the analysis. These are listed in table 1. Pulmonary artery pressure was determined by preoperative cardiac catheterisation in 128 patients $(64 \%)$. A further 58 patients $(29 \%)$ had pulmonary artery pressure estimated from chest radiographs by the methods described by Galloway, ${ }^{14}$ Milne, ${ }^{15}$ and Simon. ${ }^{16}$ Each of these variables was matched against the overall survival of the group to ascertain its prognostic significance. The patient's entry to the study was defined as the time of the first valvotomy operation. The end point was death. In contrast with the convention of previous reports, a second valvotomy or mitral valve replacement was not considered as an end point because the second operation was carried out by the same procedure as the first within 10 years and most valve replacements were performed more than 10 years after the first operation. Cases lost to follow up were included as censored observations.
STATISTICAL ANALYSIS

The information was analysed with the Statistical Package for Social Sciences Extended (SPSSX) ${ }^{17}$ at $\stackrel{0}{?}$ the University of Liverpool. Survival analysis was performed by the actuarial method of Berckson and $\underline{\underline{F}}$ Gage. ${ }^{18}$ The influence of the variables listed in table $1 \frac{\bar{c}}{7}$ on survival was assessed by techniques described by $\stackrel{\mathbb{Q}}{2}$ Lee-Desu, ${ }^{19}$ where statistic D is calculated from the survival scores. $\mathrm{D}$ is asymptotically distributed as $\chi^{2} \stackrel{\mathrm{e}}{2}$

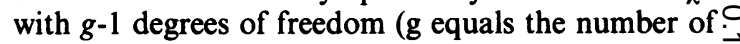
subgroups in each variable).

The independent significant variables thus obtained $\stackrel{\omega}{\sigma}$ were combined to observe their predictive value on $\overrightarrow{\vec{x}}$

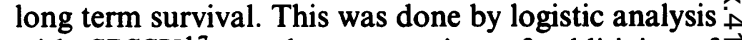
with SPSSX $^{17}$ on the assumption of additivity of ir effects on log odds scale - that is, risk factors multi- $A$ plicative on odds scale. This assumption gave an acceptable goodness of fit of the observed survivalo data-namely, $2\left(\chi^{2}=26.8,26 \mathrm{df}\right.$, NS). The $5 \%$ level of probability was taken as significant.

\section{Results}

POPULATION AND VARIABLES

Two hundred patients were entered in the study. The mean age at operation was 29 (range 17-40) years. The female to male ratio was $4: 1$.

The duration of symptoms before valvotomy (palpitations, paroxysmal nocturnal dyspnoea, and dys-ô pnoea on exertion) was five years or less in 100 patients $(50 \%),>5-10$ years in $48(24 \%),>10-15 \%$ years in $23(11.5 \%),>15-20$ years in eight $(4 \%)$; and more than 20 years in six (3\%).

One hundred and thirty patients $(65 \%)$ had sinus rhythm, $65(33 \%)$ atrial fibrillation, and four $(2 \%))_{-}^{x}$ variable rhythm. In one patient the preoperative elec-3.3. trocardiogram was unavailable. A systolic pulmonary artery pressure of less than $50 \mathrm{~mm} \mathrm{Hg}$ was classified as "mild" pulmonary hypertension (80 patients, $40 \%$ ), $50-79 \mathrm{~mm} \mathrm{Hg}$ as "moderate" (78 patients, $39 \%$ ), and $80 \mathrm{~mm} \mathrm{Hg}$ or more as "severe" (28 patients, $14 \%)$. 긍

Seventy one patients (35\%) had congestive cardiac failure at the time of operation (NYHA criteria $N^{N}$ classes III and IV). In $28(14 \%)$ congestive cardiac N failure persisted after valvotomy; 38 patients $(19 \%)$ N developed it after operation; 37 patients $(19 \%) \mathrm{did}^{\omega}$ not suffer from it at any time. In the remaining $54 \%$ patients $(27 \%)$, although none was in heart failure before valvotomy, the functional class was not specifically recorded at the last follow up exam -ination.

Twenty seven patients $(13 \%)$ had had at least one significant systemic embolic event before operation $\frac{\text { ? }}{0}$ and $20(10 \%)$ developed embolism during the follow up period. One patient developed emboli both before 
and after valvotomy. Seventeen out of 47 patients with emboli were in sinus rhythm; 133 patients $(66 \%)$ did not suffer from embolic episodes. For 19 patients $(10 \%)$ lost to follow up the history relating to embolism was uncertain.

Forty eight patients $(27 \%)$ had appreciable mitral regurgitation, $30(15 \%)$ had associated aortic stenosis, four had tricupsid stenosis, and four had multiple valves affected. One hundred and fourteen patients $(57 \%)$ had pure mitral stenosis without clinical evidence of appreciable regurgitation. The degree of calcification was recorded as nil to minimal in 148 patients $(\mathbf{7 4 \%})$ and moderate to severe in 47 patients $(27 \%)$. This information was not available for five patients.

The extent of valve fibrosis at the time of operation was recorded as "mild" (46 patients, $23 \%$ ), "moderate" (40 patients, $20 \%$ ) or "severe" (110 patients, $55 \%$ ). Records were not available for four patients.

One hundred and six patients $(53 \%)$ were operated on with Tubb's dilator and $68(34 \%)$ by finger fracture of the fused valve. In the remaining 26 patients $(13 \%)$ other methods were used and $14(7 \%)$ of them had mitral and aortic valvotomies performed at the same time.

Long term anticoagulation was given to 48 patients (24\%); 66 patients $(33 \%)$ did not receive any anticoagulation. Of the remaining 86 patients $(43 \%)$, some had received anticoagulation for two years only $^{20}$ and others had received either none at all or only intermittent anticoagulation and were excluded from this part of the analysis.

Twenty seven patients (14\%) had a second valvotomy-10 within the first five years, 10 within the next five years, four 10 to 15 years, one between 15 to 20 years, and two more than 25 years after operation. Thirty two patients $(16 \%)$ had mitral valve replacements-18 10-19 years and 14 more than 20 years after operation.

At the time of the last follow up examination or death, 107 patients $(53 \%)$ had atrial fibrillation, 81 $(40 \%)$ sinus rhythm, and seven $(3 \%)$ other rhythms. The ECGs of five patients were not available.

\section{ANALYSIS OF SURVIVAL}

\section{Follow up}

One hundred and ten patients were followed up, either to the present day or to the time of death. Of the original group, 20 patients had been lost by five years and 84 by 10 years. Thereafter only a further six patients were lost. The high rate of fallout from the study from 5 to 10 years is partly explained by the reorganisation of the referral system in the National Health Service and the very wide area covered by the Liverpool hospitals providing a regional cardiological service. We have taken the fallout into account in our statistical analysis by the actuarial method referred to earlier.

Fifty nine patients were known to have died; 17 patients died during the perioperative period and 42 died subsequently. Of these 42,28 had died of cardiovascular causes and the cause of death was not clear in the remaining 14 patients.

\section{Variables predicting long term survival}

Independent Variables (figure) Only seven of the 17 variables were found to have independent correlation with survival. These were: (1) preoperative cardiac rhythm; (2) congestive cardiac failure; (3) associated cardiac conditions; (4) type of operation; (5) pulmonary artery pressure; (6) mitral valve calcification; and (7) anticoagulation treatment. Sex (a slight preponderance of women) had only a non-significant association with survival $(p<0.08)$. The duration of symptoms before operation was not a significant factor in long term prognosis $(p<0.44)$.

\section{Combination of significant variables}

We were able to observe the collective influence of significant variables by logistic analysis on only 105 cases, as 95 were rejected because of missing data. The results are shown in table 2 . In a subgroup of 25 patients, all of whom had valvotomy performed by Tubb's method and received anticoagulation treatment, the probability of long term survival was highest among patients in sinus rhythm, without congestive cardiac failure or severe pulmonary artery pressure, as shown in table 3. This, however, may not represent the experience of the whole group.

\section{Discussion}

In our population the clinical predictors of prolonged survival were: pure mitral stenosis; preoperative sinus rhythm; mild to moderate rather than severe pulmonary arterial hypertension; absence of congestive cardiac failure at the time of operation, and anticoagulation treatment. Patients with valve calcification had a poor outcome. A transventricular approach with a mechanical dilator to perform valvotomy gave better results than finger splitting or other approaches.

Although our final sample is modest in size and contains many cases lost to long term follow up the results point to important aspects in the management of mitral stenosis. The incidence of atrial fibrillation in our series was higher than has been previously reported. ${ }^{21}$ Twenty four per cent of patients suffered systemic embolism, a figure similar to that found in other series. ${ }^{22-24}$ Anticoagulation had a strong favourable influence on prognosis. In view of the fact that this influence was observed even in patients in 

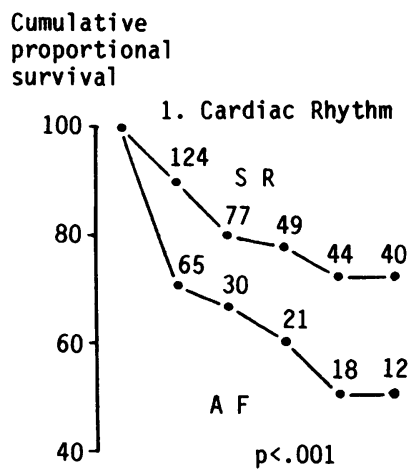

2. Cardiac Failure

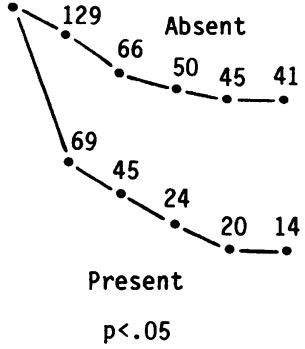

3. Asso. Cardiac Cond.

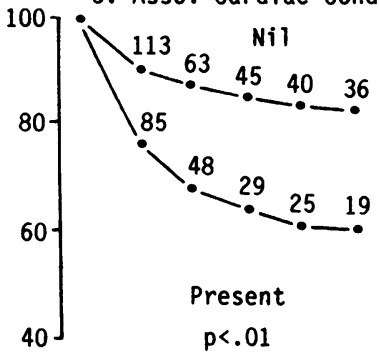

4. Type of Operation

i 106 Tubbs

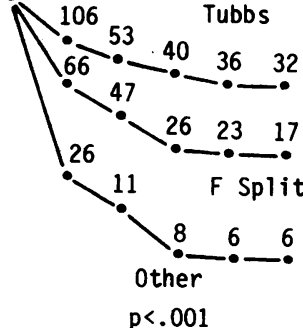

5. P A Hypertension

6. Mitral Calcification
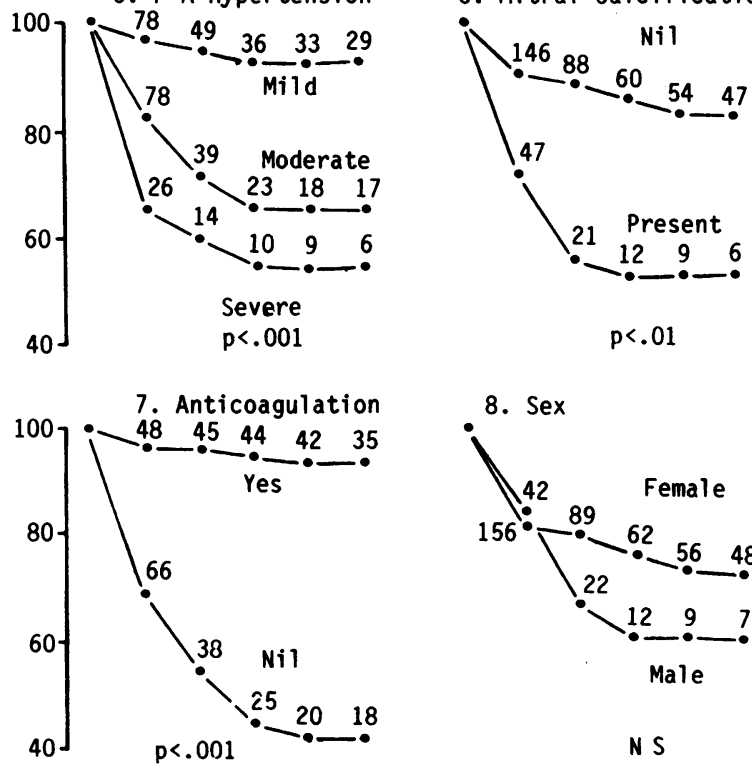

8. Sex

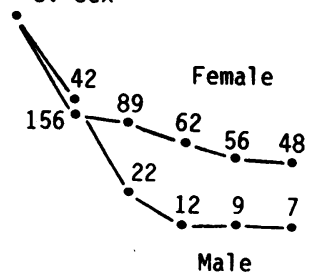

N S

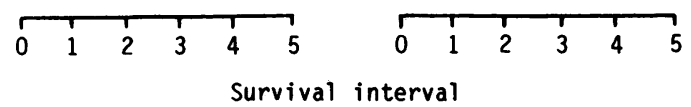

Influence of independent variables on survival. Survival intervals (years): $1=0-5 ; 2=>5-10 ; 3=>10-15 ; 4=>15-20$; $5=>20$. SR-sinus rhythm; $A F$-atrial fibrillation; asso. cardiac cond.-associated cardiac conditions; $F$ split-finger splitting; $P A-$ pulmonary artery. 
Table 2 Probability of 20 or more years' survival, based on 105 cases

\begin{tabular}{llll}
\hline CCF & $\begin{array}{l}\text { Cardiac } \\
\text { arrhythmias }\end{array}$ & Anticoagulants & $\begin{array}{l}\text { Estimated } \\
\% \text { survival }\end{array}$ \\
\hline No & Absent & No & 47.6 \\
No & Absent & Yes & 90.0 \\
No & Present & No & 15.62 \\
No & Present & Yes & 64.6 \\
Yes & Absent & No & 23.0 \\
Yes & Absent & Yes & 74.6 \\
Yes & Present & No & 5.8 \\
Yes & Present & Yes & 37.5 \\
\hline CCF-congestive cardiac failure.
\end{tabular}

sinus rhythm, the case for offering anticoagulation treatment to all patients with mitral stenosis, inrrespective of rhythm, history of embolic events, or cardiac failure, would appear to be strengthened.

Our observations that preoperative congestive cardiac failure and severe pulmonary arterial hypertension are markers of poor prognosis challenges the teaching ${ }^{21}$ that mitral valve surgery should be undertaken only if medical treatment fails to control symptoms. Our results support the view that early intervention is desirable. ${ }^{25} 26$

As regards actual operative technique, the study supports the current preference for a transventricular approach with a mechanical dilator ${ }^{27}$ rather than other methods. ${ }^{28}$

In contrast to the findings of Cummerford et al, ${ }^{13}$ our results suggest that extent of fibrosis of the mitral valve apparatus has no bearing on long term survival and that the high level of pulmonary artery pressure is indeed associated with a poor prognosis.

We conclude that closed mitral valvotomy by the transventricular approach with a mechanical dilator may be associated with an excellent long term outcome. Most of the predictors of survival after operations are available from clinical examination, the chest radiograph, and the ECG. Although open heart surgery has largely displaced closed mitral valvotomy, the latter still has a part to play in the management of mitral stenosis, especially in countries with limited resources.

Table 3 Probability of 20 years' survival with Tubb's operation and with anticoagulation treatment, based on 25 patients

\begin{tabular}{llll}
\hline $\begin{array}{l}P A \text { pressure } \\
(\mathrm{mm} \mathrm{Hg})\end{array}$ & CCF & Arrhythmias & $\begin{array}{l}\text { Estimated } \\
\% \text { survival }\end{array}$ \\
\hline$<80$ & No & Absent & 95.1 \\
$<80$ & No & Present & 89.6 \\
$<80$ & Yes & Absent & 81.2 \\
$<80$ & Yes & Present & 68.5 \\
$\geqslant 80$ & No & Absent & 87.6 \\
$\geqslant 80$ & No & Present & 61.0 \\
$\geqslant 80$ & Yes & Absent & 75.8 \\
$\geqslant 80$ & Yes & Present & 40.9 \\
\hline
\end{tabular}

We are grateful to our colleagues in the cardiothoracic unit at Broadgreen Hospital for allowing us to include their patients in our analysis and to all the physicians and family practitioners who cooperated in completing the postal questionnaire. We would like to thank Professor $M$ Lye of the department of geriatric medicine, without whose encouragement and help this paper could not have been prepared and Mr CR West of the biostatistics unit in the department of medicine for his statistical advice. We are grateful to Miss Andrea Stewart and Miss Catherine Fry for typing the manuscript with their usual speed and accuracy.

\section{References}

1 Ward C, Hancock BW. Extreme pulmonary hypertension caused by mitral valve disease. Natural history of results of surgery. Br Heart $J$ 1975;37:74-5.

2 Heger JJ, Wann LS, Weyman AE, Dillon JC, Feigenbaum $\mathrm{H}$. Long term changes in mitral valve area after successful mitral commissurotomy. Circulation 1979;53:443-8.

3 Montoya A, Mulet J, Pifarre R, Moran JM, Sullivan HJ. The advantages of open mitral commissurotomy for mitral stenosis. Chest 1979;75:131-4.

4 Selger A, Conn KE. Natural history of mitral stenosis: a review. Circulation 1972;45:878-90.

5 Anonymous. Mitral valve surgery in developing countries. Lancet $1984 ; \mathrm{i}: 1160-1$.

6 Agarwal BL. Rheumatic heart disease unabated in developing countries. Lancet 1981;ii:910-1.

7 Wilkins EJL, Strang JIG. The cardiologist in the third world. Br Med J 1984;289:609-11.

8 Roberts WC. Mitral commissurotomy-still a good operation. Am J Cardiol 1983;52:A9-10.

9 Bonchek LI. Current status of mitral commissurotomy, indications, techniques and results. $\mathrm{Am} J$ Cardiol 1983;52:411-5.

10 Nathaniels EK, Moncure AC, Searnell JG. A fifteen year follow up study of closed mitral valvuloplasty. Ann Thorac Surg 1970;10:27-32.

11 Ellis LB, Singh JB, Morales DD, Harcken DE. Fifteen to twenty year study of one thousand patients undergoing closed mitral valvuloplasty. Circulation 1973;48:357-62.

12 John S, Bashi S, Muralidheran T, et al. Closed mitral valvotomy: early results and long term follow up of 3724 consecutive patients. Circulation 1983;68:891-6.

13 Commerford PJ, Hastie T, Beck W. Closed mitral valvotomy. Actuarial analysis of results in 654 patients over 12 years and analysis of pre-operative predictors of long term survival. Ann Thorac Surg 1982;33:473-9.

14 Galloway RW. Mitral stenosis. The radiological assessment and correlation with the pressure changes in the lesser circulation. MD thesis, University of Liverpool, 1961.

15 Milne ENC. Physiological interpretation of the plane radiograph in mitral stenosis including a review of criteria for the radiological estimation of pulmonary arterial and venous pressures. Br J Radiol 1963;36:902-7.

16 Simon M. The pulmonary vessels. Their haemodynamic evaluation using routine radiographs. Radiol Clin $N$ Am 1963;1:363-70. 
17 University of Chicago. Statistical package for the social sciences extended (SPSSX). Users guide. London: McGraw-Hill, 1983.

18 Berkson J, Gage R. Calculation of survival rates for cancer. Proc Mayo Clin 1950;25:270-6.

19 Lee E, Desu M. A computer program for comparing K samples with right-censored data. Comp Prog Med 1972;2:315-21.

20 Coulshed N. Disorders of mitral valve function. Practitioner 1982;226:407-17.

21 Braunwald E. Valvular heart disease. In: Braunwald E, ed. Heart disease: a text book of cardiovascular medicine. Philadelphia: WB Saunders, 1980:1099-105.

22 Wood P. An appreciation of mitral stenosis. Br Med J 1954;i:1051-63.

23 Casella L, Abelmann WH, Ellis LB. Patients with mitral stenosis and systemic emboli. Arch Intern Med 1964;114:773-6.
24 Abernathy WA, Willis PW. Thromboembolic complication of rheumatic heart disease. In: Likof W, ed. Cardiovascular clinics 5: Valvular heart disease. Philadelphia: CA Davis, 1973:131.

25 Spencer FL. A plea for early open mitral commissurotomy. Am Heart J 1978;95:668-70.

26 Mullins EM, Glancy DL, Higgs LM, Epstein SE, Morrow AC. Current results of operation for mitral stenosis, $\varrho$ clinical and haemodynamic assessments in 124 con- in secutive patients treated by closed commissurotomy, open commissurotomy or valve replacement. Circulation? 1972;46:298-308.

27 Logan A, Turner R. Surgical treatment of mitral stenosis with particular reference to the transventricular ap-proach with a mechanical dilator. Lancet 1959;ii:874-8.

28 Baker LA, Brock RC, Campbell M. Valvotomy for mitral stenosis. A report of six successful cases. Br Med 1950;i:1283-7. 